\title{
MATHEMATICAL METHOD OF ANALYSING FORMS OF THE RURAL SETTLEMENTS OF BENON JANOWSKI
}

One of the pioneers in the mathematically based study of forms taken by rural settlements was Benon Janowski, the student of the great Polish geographer Eugeniusz Romer. The work of Benon Janowski is nowadays almost completely forgotten, because his activity took place in the period when Poland did not exist as a sovereign state. His concepts and theories, which came several decades ahead of the similar proposals of the European and American geographers, were published solely in Polish, and thus were not known to the international forum.

In the study published at the beginning of the century, entitled "On the shapes of settlements" (1903) Janowski proposed a geometrical-genetic classification, accounting for both the shape and the setting of fields and roads, and the origin of the settlements. In his opinion, among all the factors influencing the shape of settlements the most important role is played by transportation, and more precisely - by the setting of roads, which in a synthetic manner reflects the character of the environment, both geographical and social. That is why Benon Janowski considered that the best method for defining the shape of the settlements is "the method of chronopones, i.e. the lines of equal effort", since chronos is the Greek word for time, while ponos means effort or toil.

The method is based upon the assumption that the distance from the centre of the settlement to its boundaries is expressed not only in time, but also in work and costs, which must be borne in order to cover this distance. It might in this context be admitted that a certain time $t$ corresponds on the average to the work $p$. Thus, the product of work and time, $p \cdot t$, reflects the effort necessary for a human being to cover distance. In case when transport means are changed this expression can be transformed into corresponding [other] costs.

The starting point of the concept of B. Janowski is a model situation, in which it is assumed that rural settlements are located on an ideal plain, where natural and economic conditions are everywhere alike. If in a definite place $M$ there exist advantageous conditions for establishing a settlement, the measure of land value will only be constituted by distance. Hence, land 


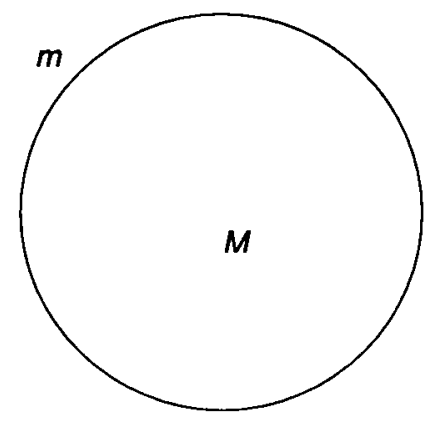

Fig. 1. An ideal settlement model.

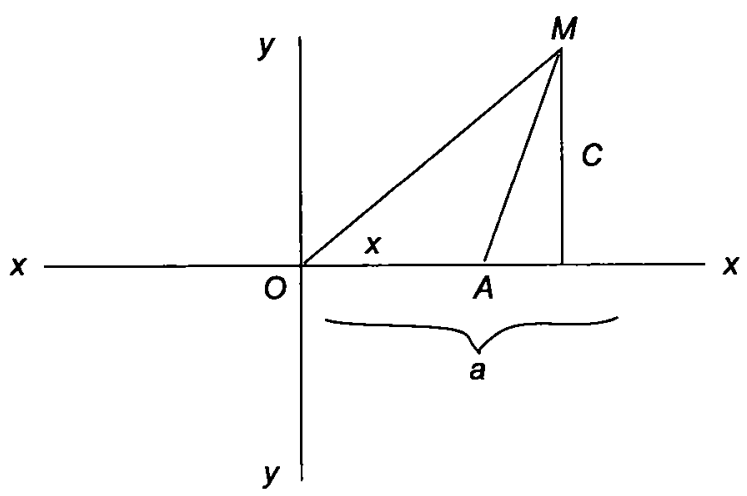

Fig. 2. A single-road settlement in a mathematical setting.

locities is defined by the relation $c=m c^{\prime}$. How, therefore, one should select the travel course in order to get to the point $M$ in a possibly shortest time?

Time needed to cover the distance of $O A M$ is expressed as

$$
t=\frac{x}{c}+\frac{\sqrt{(a-x)^{2}+b^{2}}}{c_{1}}=\frac{1}{c}\left(x+m \sqrt{(a-x)^{2}+b^{2}}\right)
$$

In order to determine when the time will be the shortest, we differentiate the equation expressing travel time:

$$
\begin{gathered}
\frac{d t}{d x}=\frac{1}{c}\left\{1+m \frac{1}{2}\left[(a-x)^{2}+b^{2}\right]-\frac{1}{2} 2(a-x)(-1)\right\}= \\
=\frac{1}{c}\left\{1-\frac{m(a-x)}{\sqrt{(a-x)^{2}+b^{2}}}\right\}=0 \\
\sqrt{(a-x)^{2}+b^{2}}=m(a-x)
\end{gathered}
$$




$$
\begin{aligned}
& \frac{d^{2} t}{d x^{2}}=\frac{m}{c} \frac{b^{2}}{\left[(a-x)^{2}+b^{2}\right]^{3 / 2}}
\end{aligned}
$$

Since for all values of $x$ the magnitude $\frac{d^{2} t}{d x^{2}}$ is positive, the formula (1) defines the minimum at $t=\frac{1}{c}\left(a+b \frac{m \pm 1}{\sqrt{m^{2}-1}}\right)$

Now we will consider the first quarter of the coordinate plane only, since in the other ones the situation will get repeated, because of symmetricity with respect to the axes $x x$ and $y y$.

As $a>0, b>0$, we obtain for the main minimum

$$
\min t=\frac{1}{c}\left(a+b \frac{m^{2}-1}{\sqrt{m^{2}-1}}\right)=\frac{1}{c}\left[a+b \sqrt{m^{2}-1}\right] \text {, where } x=a-\frac{b}{\sqrt{m^{2}-1}}
$$

If we want now to find the geometrical image of all the points for which time (effort) is the same, we will treat $t$ as constant, while $a$ and $b$ will be independent variables, with $a+b \sqrt{m^{2}-1}=t c$.

$b=-\frac{1}{\sqrt{m^{2}-1}}(a-c t)$ is the straight line equation.

This holds as long as $x>0$, i.e. $a>\frac{b}{\sqrt{m^{2}-1}}$.

1) When $a=\frac{b}{\sqrt{m^{2}-1}}$, then $x=0$, meaning that only one path is used - i.e. the straight line linking the points $O$ and $M$.

2) When $a<\frac{b}{\sqrt{m^{2}-1}}$, then $x<0$, and this case is of no importance for us.

Hence, the chronopone is composed of two parts:

- a segment of a straight line for $x=a-\frac{b}{\sqrt{m^{2}-1}}>0$, and

- an arc of a circle, having the radius $r=t c$ for $x=\frac{a-b}{\sqrt{m^{2}-1}} \leq 0$.

Thus, a chronopone will have altogether the shape of the line $A B C D$ (Fig. 3). 


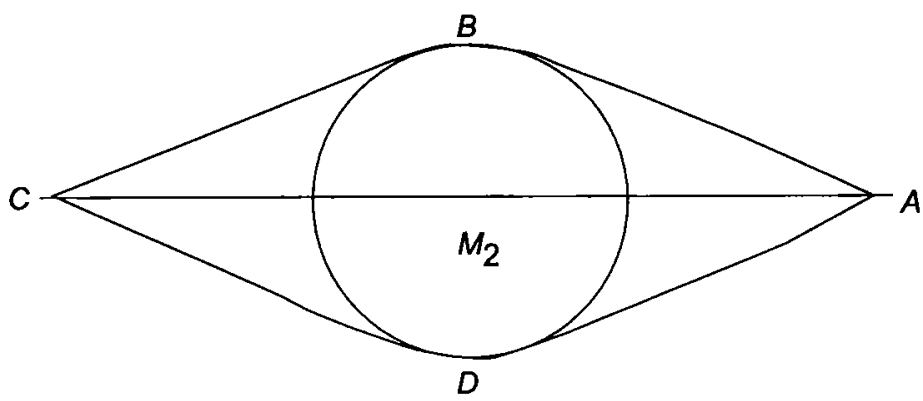

Fig. 3. A model of a settlement located along a single road.

This is a shape taken by the settlements situated along a single, main road. There are, however, rural settlements of a different shape, namely those with a number of roads. That is why one should consider now the settlement $M_{3}$, located on two crossing roads. This situation is most often encountered in the traditional settlement systems, originating yet from the medieval times.

The case of such a settlement is entirely founded upon the previous one, and the whole calculus previously deployed can be applied here. The road $B D$ exerts, namely, the very same influence as the road $A C$, and so the line of chronopone should be drawn in the same manner as in the preceding case. The two chronopones will therefore take the shape of the line $A B C D$ (Fig. 4).

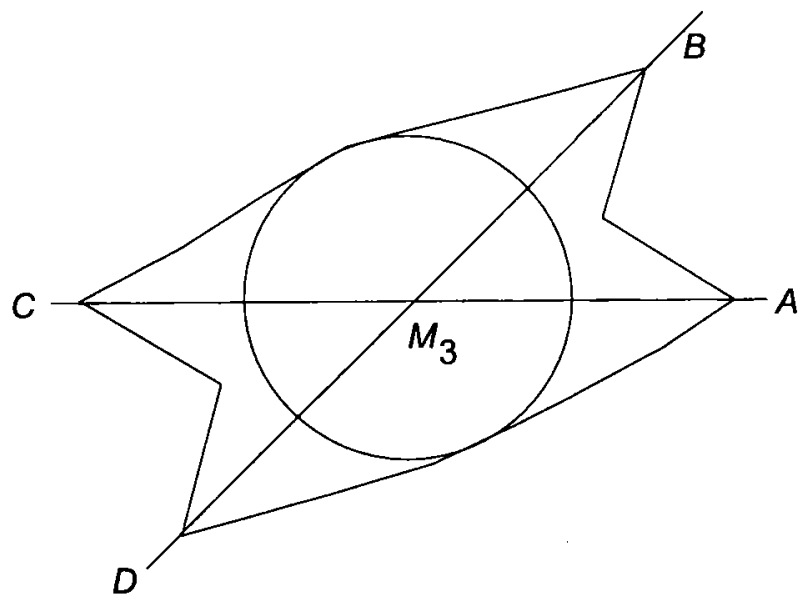

Fig. 4. A model of a settlement located on the crossing of two roads.

Hence, irrespective of the number of roads crossing the settlement $M_{3}$, one should always construct the chronopone in accordance with a unified, and also a very simple, scheme. Thus, one draws from the centre of the settlement a circle having the radius corresponding to the average velocity on the given area, that is - the distance that can be covered during $t$ hours 
of effort (work) when no road is used. Next, the distance $M_{3} A$ is defined on one of the roads, corresponding to that which can be covered with the same effort. Similarly for other roads. Then, from the points thus obtained tangential lines are drawn to the circle. The figure, which is formed by the tangential lines, is the desired chronopone.

Construction is very simple. Knowing the course of chronopones one can to certain degree reconstruct from the plans of the settlements the origins of their emergence and development. The greater the extent to which the settlements live their own life, the more they ought to take the shapes corresponding to chronopones. Conversely, the stronger the external influences, the more the settlements will diverge from the ideal setting, described by the chronopones.

Benon Janowski verified thereafter his concept on the map of the Drohobycz (Drogobič) county, located in the south- eastern corner of the pre-war Poland, the map having the scale of 1:75 000. Among 53 villages considered there were as many as 31 , that is - almost $60 \%$ - which had a chronopone outline. In this group of 31 villages Janowski distinguished two types of settlements: the strip and the nodal settlements. The strip villages are as a rule observed in the mountains. Within the plains, on the other hand, the settlements usually have much more room for the spatial development, due to which they take the shape of a "higher order". They do not coalesce, leaving more or less space between them. This setting was called nodal by Janowski. Thereby, it is demonstrated that the shapes of settlements are primarily a derivative of the social and economic processes, and not only a function of the physico-geographical conditions.

The study of the settlement shapes with the mathematical methods reappeared, mainly owing to the British and American geographers, as late as in the 1960s, with the main attention, however, being paid to urban areas. Contemporary geographers, when analysing objects located on the surface of the Earth, and the settlements of different types are definitely just such objects, are interested also in one of the most significant features, constituted by the course of the object's outside boundaries. The flat shape of the object situated on the surface of the Earth is obtained from the orthogonal projection of this object onto the plane of the map. Consequently, some flat figure is obtained, bounded by a closed curve or a piece-wise linear contour, or a number of such closed contours. Thus, this figure can be compact or multi-compact, depending upon the number of contours surrounding the figure (see Golachowski, Kostrubiec, Zagożdżon, 1974).

Similarly as Benon Janowski, the contemporary geographers have been looking for a universal indicator of the settlement shape, which would allow for an explanation of their origins and development dynamics. And so, J.P. Gibbs (1961) made use of just few, selected basic parameters of a figure (surface, periphery, length of the longest diameter, radii of the circumscribed and inscribed circles corresponding to the figure) to obtain several ratios, in which the fundamental pairs of measurements appear (surface and pe- 
riphery, surface and the longest diameter, the two radii). Then, in turn, P. Haggett (1965) made an attempt of characterising shapes with the three ratios mentioned.

Other authors, R. Boyce and W.A.C. Clarke (1964), introduced an indicator based upon the radial measurements of the distance between the contour of the figure and its gravity centre. Gravity centre was determined by them in a mechanical manner, which largely simplified the study. Then, in turn, D.R. Lee and G.T. Salee (1970), who referred to the metric distance of the symmetric difference of two sets, proposed an index resulting therefrom as the indicator of the shape of the figure.

It should be noted here that this particular measure was introduced earlier by the Polish mathematicians from the Lwów school of mathematics, E. Marczewski and H. Steinhaus (1958). The respective indicators are obtained by carrying out a comparison between two shapes, the standard and the unknown one, the former being a circle, a square, or a triangle. This concept refers directly to the work on the shapes of the settlements, initiated by the German geographer G. Kohl (1841). In such an approach shapes can be analysed for the degree of their "circularity", "squareness", or "triangularity".

The concepts of measuring the shapes of settlements mentioned above were similar to those of Benon Janowski. Yet, the solution proposals of the Polish geographer from the beginning of the $20^{\text {th }}$ century were broader in their applicability and postulated the use of a more refined methodology. The theoretical apparatus, borrowed from classical physics, and the differential calculus, made it possible not only to define the shapes of settlements, but also to explain their origins in a broad spatial context, encompassing both the natural, and the social, as well as economic questions. Simultaneously, this was equivalent to opening the way for application of physical models in geographical study, and thus to appearance of the so called social physics.

\section{REFERENCES}

B oyce P.B., Clark W.A.C., 1964, The Concept of Shape in Geography, Geographical Review, 54, 561-572.

Gibbs J.P., 1961, Urban Research Methods, J. Wiley and Sons, New York.

Gola chowski S., Kostrubiec B., Zag ożd z on A., 1974, Metody badań geograficznoosadniczych [Methods of geographical and settlement system study], PWN, Warszawa.

Hagge tt $\mathrm{P}_{\text {., }}$ 1965, Locational Analysis, E. Arnold, London.

Janowski B., 1903, O kształtach osad [On the shapes of settlements], Wista, 17(5), 521-546.

Kohl J.G., 1841, Der Verkehr und die Ansiedlungen der Menschen, ihre Abhangigkeit von der Gestalt der Oberfläche, Arnold Buchhandlung, Dresden.

Le e D.R., S a le e G.T., 1970, A Method of Measuring Shape, Geographical Review, 60(4), 555-563.

Marczewski E., Ste in ha u H, 1958, O odległości systematycznej biotopów [On systematic distance between biotopes], Zastosowania Matematyki, 4(3), 195-203. 